\title{
JAM3 methylation status as a biomarker for diagnosis of preneoplastic and neoplastic lesions of the cervix
}

\author{
Aijun Yin ${ }^{1}$, Qing Zhang ${ }^{1}$, Xiangnan Kong ${ }^{2}$, Lin Jia ${ }^{1}$, Ziyan Yang $^{1}$, Lihua Meng ${ }^{1}$, \\ Li Li ${ }^{3}$, Xiao Wang ${ }^{3}$, Yunbo Qiao ${ }^{1}$, Nan Lu${ }^{4}$, Qifeng Yang ${ }^{5,6}$, Keng Shen ${ }^{7}$, Beihua Kong ${ }^{1}$ \\ ${ }^{1}$ Department of Obstetrics and Gynecology, Qilu Hospital, Shandong University, Jinan, P.R. China \\ ${ }^{2}$ Laboratory Medicine Center, Qilu Hospital of Shandong University, Qingdao, P.R. China \\ ${ }^{3}$ Institute of Pathology and Pathophysiology, Shandong University School of Medicine, Jinan, P.R. China \\ ${ }^{4}$ Institute of Diagnostics, Shandong University School of Medicine, Jinan, P.R. China \\ ${ }^{5}$ Department of Breast Surgery, Qilu Hospital, Shandong University, Jinan, P.R. China \\ ${ }^{6}$ Pathology Tissue Bank, Qilu Hospital, Shandong University, Jinan, P.R. China \\ ${ }^{7}$ Department of Obstetrics and Gynecology, Peking Union Medical College Hospital, Chinese Academy of Medical Sciences and \\ Peking Union Medical College, Beijing, P.R. China
}

Correspondence to: Beihua Kong, e-mail: kongbeihua@sdu.edu.cn

Keywords: JAM3, cervical neoplasia, methylation, triage, complementary

Received: August 16, 2015

Accepted: October 14, 2015

Published: October 27, 2015

\section{ABSTRACT}

DNA methylation is clinically relevant to important tumorigenic mechanisms. This study evaluated the methylation status of candidate genes in cervical neoplasia and determined their diagnostic performance in clinical practice. Cervical cancer and normal cervix tissue was used to select the top 5 discriminating loci among 27 loci in 4 genes (CCNA1, CADM1, DAPK1, JAM3), and one locus of JAM3 (region M4) was identified and confirmed with 267 and 224 cervical scrapings from 2 independent colposcopy referral studies. For patients with atypical squamous cells of unknown significance and those with low-grade squamous intraepithelial lesion, with JAM3-M4 compared to a triage marker of hrHPV testing, the specificity for cervical intraepithelial neoplasia 3 CIN3 and cancer cases (CIN3+) / no neoplasia and CIN1 (CIN1-) was significantly increased, from 21.88 to 81.82 and 15.38 to 85.18 , respectively. The corresponding positive predictive value (PPV) was increased from 26.47 to 57.14 and 18.52 to 63.64 , respectively. For hrHPV-positive patients, compared to a triage marker of cytology testing, JAM3-M4 showed increased specificity and PPV, from 30.67 to 87.65 and 38.82 to 82.14 , respectively. We assessed whether JAM3-M4 could distinguish productive from transforming CIN2; the coincidence rate of JAM3-M4 and P16 was as high as $60.5 \%$.

\section{INTRODUCTION}

Cervical cancer is a leading cause of cancer deaths in women worldwide, with an estimated 528,000 new cases and 266,000 deaths annually; $85 \%$ occur in developing countries $[1,2]$. As a developing country, China has a high incidence of cervical cancer, 7.5/100,000 women, and mortality 3.4/100,000 women, especially in rural areas because of lack of proper screening [3]. The incidence of cervical cancer has reached $81 / 100,000$ people in some areas in China [4]. By 2030, cervical cancer is expected to be responsible for the death of 474,000 women annually, with more than $95 \%$ of these deaths anticipated to occur in low- and middle-income countries [5]. Thus, establishing a proper screening strategy is of great importance to reduce the cancer burden in China.

The most widely used screening methods for cervical cancer are the cytology-based Pap smear and high-risk human papillomavirus (hrHPV) testing. However, both methods have drawbacks. In one study, of 
more than 60,000 women, cytology-based Pap smear screening did not detect almost half of the cases of cervical intraepithelial neoplasia 2 (CIN2), CIN3 and cancer (CIN2+) and only $20 \%$ of the women with an abnormal Pap smear had histologically confirmed CIN2+ [6]. Moreover, cytology testing is often subjective for a great number of professional cytologists. HrHPV testing of cervical scrapings can improve the sensitivity of cervical screening $[7,8]$; however, the lifetime risk of hrHPV infection is estimated to be about $80 \%$ [9] and the screening hrHPV test cannot discriminate between infections that would transform into cancer and transient infections. Such a less specific screening test may lead to a substantially heavy burden on health care resources, such as unnecessary referral to colposcopy. To avoid missed diagnoses and over-diagnoses, other triage and/or complementary biomarkers that are molecularly based and not morphology based are urgently needed.

DNA hypermethylation of the promoter and $5^{\prime}$ region of tumor suppressor genes is an epigenetic modification that may be involved in the early phase of carcinogenesis, including cervical carcinogenesis [10-13]. Epigenetic changes occur during each of stage of cervical cancer [14], and various genes are silenced by promoter methylation at distinct stages in the transformation process $[15,16]$. The accumulation of epigenetic alterations in the host genome promote the progression to invasive cervical cancer [17]. The most appropriate screening biomarkers of DNA methylation in cervical carcinogenesis appear during the progression to high-grade dysplasia. A series of studies $[10,14,18,19]$ reviewed the epigenetic alterations in premalignant and malignant lesions of the cervix but were heterogenous and results were inconsistent for most genes. Methylation frequencies for the same gene vary widely among studies because of the different loci chosen [20], different genetic backgrounds of various populations $[21,22]$, specific features of assay protocols, or other unidentified factors.

In the present study, we aimed to identify highly distinguishable DNA methylation loci of genes that may be clinically practical as biomarkers of cervical cancer, especially in geographic locations where quality-controlled cytology testing is absent and a follow-up strategy for HPV-positive women is not defined [23]. Previously reported methylation status in cervical neoplasia identified cyclin A1 (CCNA1) [24-26], cell adhesion molecule 1 (CADM1) [20, 26-28], death-associated protein kinase $1(D A P K 1)[25,26,29]$ and junctional adhesion molecule 3 (JAM3) [13] as the most discriminating and stable biomarkers. From microarray data from The Cancer Genome Atlas and a review of the literature to identify the most discriminating loci, we chose various loci of these 4 genes for in-depth investigation by methylation-specific PCR (MSP) of cervical cancer and normal cervical tissue. The markers were further evaluated and confirmed with cervical scrapings from two colposcopy referral studies including 267 and 224 cervical scrapings, respectively (Predictors 1 [P1] and Predictors 2 [P2]), and the most promising marker was evaluated to identify its potential as a triage or complementary marker in hrHPV or cytology testing. Finally, the discriminating marker was validated by pyrosequencing and assessed for potential to triage the controversial CIN2.

\section{RESULTS}

\section{Sample characteristics}

Clinicopathological data for tissue specimens are in Table 1. Clinicopathological data and available hrHPV and cytology results for cervical scrapings are in Table 2.

\section{MSP of normal cervical and cervical cancer tissue}

MSP analysis of specimens from 27 patients with normal cervical tissue and 43 with cancer tissue is in Table 3. Promising markers were chosen on the basis of $P$ value and comparison of methylation frequency. Liquid-based cytology specimens were the most frequent specimens used for cervical cancer screening and triage. The specific loci for each gene were labeled M1, M2, etc. The first 5 gene loci (CADM1-M2, CADM1-M8, DAPK1-M2, $D A P K 1-\mathrm{M} 3$, and JAM3-M4) selected from the initial 27 markers were further evaluated by quantitative MSP (QMSP) in cervical scrapings (Figure 1). The methylation frequency for these loci was significantly higher in cervical cancer than normal cervical tissue (Table 3).

\section{QMSP of cervical scrapings as a screening biomarker}

QMSP for CADM1-M2, CADM1-M8, DAPK1-M2, $D A P K 1-\mathrm{M} 3$, and JAM3-M4 involved cervical scrapings from a colposcopy referral study (P1) of 267 patients. In general, the methylation ratio increased with increasing lesion severity. Particularly, JAM3-M4 was most discriminative marker (Figure 2).

To further investigate the data, we used different classifications for diagnostic groups. CIN2+/CIN1and CIN3+/CIN2- were the classifications when the end point was CIN2 and CIN3, respectively. Because of the controversy with CIN2 itself, we evaluated the classification CIN3+/CIN1-. A logistic regression model was used to explore the predictive power of methylation of the 5 loci with different diagnostic classifications. For the CIN3+/CIN1- and CIN3+/CIN2- classifications, $J A M 3-\mathrm{M} 4$ had adequate predictive power. Other genes did not add substantial information for discrimination. For the CIN2+/CIN1- classification, CADM1-M8 $(P=0.001), D A P K 1-\mathrm{M} 3(P=0.038)$ and JAM3-M4 $(P=0.011)$ showed the best discriminating power. 


\begin{tabular}{|l|c|}
\hline \multicolumn{2}{|c|}{ No. } \\
\hline Total number & 43 \\
\hline Age $($ Mean \pm SD) & $45.75 \pm 10.21$ \\
\hline FIGO & 9 \\
\hline IA & 11 \\
\hline IB & 6 \\
\hline IIA & 4 \\
\hline IIB & 5 \\
\hline IIIA & 6 \\
\hline IIIB & 2 \\
\hline IV & \\
\hline Pathological type & 35 \\
\hline Squamous carcinoma & 7 \\
\hline Adenocarcinoma & 1 \\
\hline Others & \\
\hline
\end{tabular}

Table 2: Clinicopathological data of patients with scrapings and the relative available hrHPV testing and cytology testing results

\begin{tabular}{|c|c|c|c|c|c|c|c|c|c|c|}
\hline & \multicolumn{5}{|c|}{ Predictors 1} & \multicolumn{5}{|c|}{ Predictors 2} \\
\hline & $\begin{array}{c}\text { Normal } \\
\text { No. }\end{array}$ & $\begin{array}{l}\text { CIN1 } \\
\text { No. }\end{array}$ & $\begin{array}{c}\text { CIN2 } \\
\text { No. }\end{array}$ & $\begin{array}{l}\text { CIN3 } \\
\text { No. }\end{array}$ & $\begin{array}{c}\text { Cancer } \\
\text { No. }\end{array}$ & $\begin{array}{c}\text { Normal } \\
\text { No. }\end{array}$ & $\begin{array}{l}\text { CIN1 } \\
\text { No. }\end{array}$ & $\begin{array}{l}\text { CIN2 } \\
\text { No. }\end{array}$ & $\begin{array}{l}\text { CIN3 } \\
\text { No. }\end{array}$ & $\begin{array}{c}\text { Cancer } \\
\text { No. }\end{array}$ \\
\hline Total number & 53 & 59 & 72 & 63 & 20 & 70 & 49 & 51 & 33 & 14 \\
\hline $\begin{array}{l}\text { Age } \\
(\text { Mean } \pm \text { SD })\end{array}$ & $\begin{array}{l}44.35 \pm \\
10.39\end{array}$ & $\begin{array}{l}41.88 \pm \\
8.78\end{array}$ & $\begin{array}{l}38.31 \pm \\
10.42\end{array}$ & $\begin{array}{l}40.39 \pm \\
8.49\end{array}$ & \begin{tabular}{|l}
$50.29 \pm$ \\
11.86
\end{tabular} & \begin{tabular}{|l}
$41.84 \pm$ \\
10.05
\end{tabular} & $\begin{array}{l}40.20 \pm \\
6.99\end{array}$ & $\begin{array}{l}38.39 \pm \\
8.01\end{array}$ & $\begin{array}{l}39.61 \pm \\
7.74\end{array}$ & $\begin{array}{l}46.38 \pm \\
8.73\end{array}$ \\
\hline \multicolumn{11}{|l|}{ HrHPV } \\
\hline Positive & 39 & 41 & 62 & 44 & 9 & 55 & 41 & 41 & 24 & 7 \\
\hline Negative & 6 & 10 & 1 & 1 & 0 & 5 & 1 & 0 & 1 & 0 \\
\hline \multicolumn{11}{|l|}{ Cytology } \\
\hline NILM & 10 & 16 & 10 & 3 & 1 & 21 & 19 & 9 & 5 & 2 \\
\hline ASCUS & 16 & 19 & 25 & 8 & 3 & 30 & 22 & 20 & 8 & 2 \\
\hline LSIL & 18 & 9 & 12 & 6 & 1 & 8 & 6 & 7 & 6 & 1 \\
\hline ASC-H & 3 & 2 & 5 & 14 & 1 & 2 & 2 & 3 & 4 & 3 \\
\hline HSIL & 3 & 1 & 6 & 9 & 2 & 3 & 0 & 6 & 8 & 1 \\
\hline
\end{tabular}

However, the area under the receiver operating characteristic curve (AUC) for the 3 genes combined $(\mathrm{AUC}=0.806)$ was only slightly higher than that with JAM3-M4 alone (AUC $=0.793$ ). Therefore, in the following analysis, we evaluated JAM3-M4 alone with the diagnostic groups in P1 (Figure 3A, Supplementary Table 1).
The AUC for JAM3-M4 for CIN3+/CIN1-, CIN3+/ CIN2- and CIN2+/CIN1- classifications was $0.907,0.860$ and 0.793 , respectively. The AUC for JAM3-M4 was reproducible in the two studies of $\mathrm{P} 1$ and $\mathrm{P} 2$, with similar AUC of $0.900,0.870$ and 0.765 for CIN3+/CIN1-, CIN3+/ CIN2- and CIN2+/CIN1- classifications in P2 (Figure 4A). 
(A)

$$
\frac{\mathrm{M}-\mathrm{co}}{\mathrm{M} \mathrm{U}} \frac{\mathrm{U}-\mathrm{co}}{\mathrm{M} \mathrm{U}} \frac{\mathrm{NTC}}{\mathrm{M} \mathrm{U}} \frac{\mathrm{Cl}}{\mathrm{M} \mathrm{U}} \frac{\mathrm{C} 2}{\mathrm{M} U} \frac{\mathrm{C} 3}{\mathrm{M} U} \frac{\mathrm{C} 4}{\mathrm{M} U} \frac{\mathrm{C} 5}{\mathrm{M} U}
$$

CADMI-M2

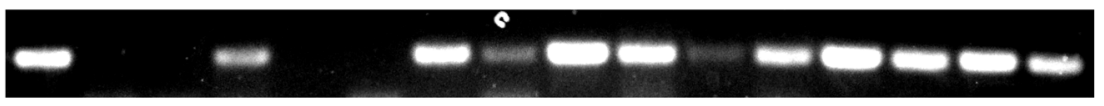

$\frac{\mathrm{M}-\mathrm{co}}{\mathrm{M} U} \frac{\mathrm{U}}{\mathrm{M} U \mathrm{U}} \frac{\mathrm{NTC}}{\mathrm{M} U} \frac{\mathrm{N} 1}{\mathrm{M} U} \frac{\mathrm{N} 2}{\mathrm{M} U} \frac{\mathrm{N} 3}{\mathrm{M} U} \frac{\mathrm{U}}{\mathrm{M} U} \frac{\mathrm{N}}{\mathrm{M} U}$

CADMI-M2

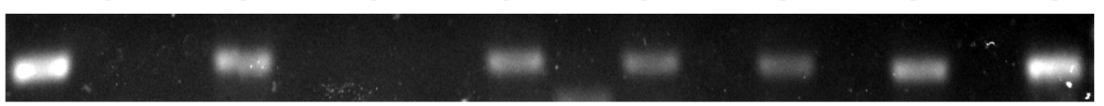

(B)

$\frac{\mathrm{M}-\mathrm{co}}{\mathrm{M} U} \frac{\mathrm{U}-\mathrm{co}}{\mathrm{M} U} \frac{\mathrm{NTC}}{\mathrm{M} U} \frac{\mathrm{Cl}}{\mathrm{M} U} \frac{\mathrm{C} 2}{\mathrm{M} U} \frac{\mathrm{C} 3}{\mathrm{M} U} \frac{\mathrm{C} 4}{\mathrm{M} U} \frac{\mathrm{C} 5}{\mathrm{M} U}$

CADMI-M8
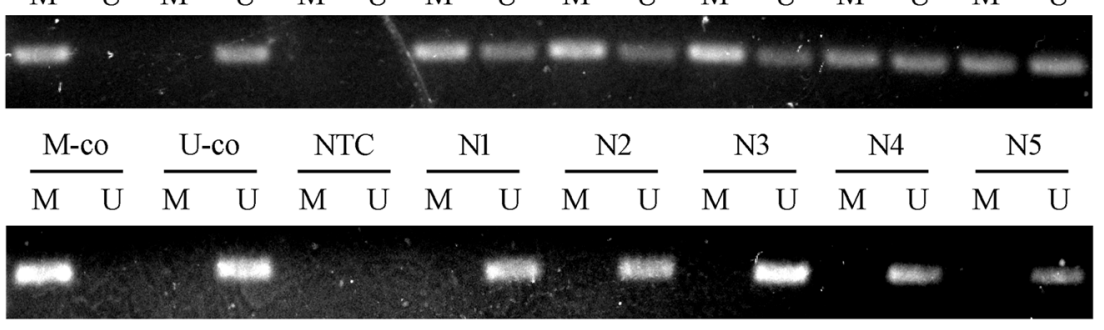

(C)

DAPK1-M2

$$
\frac{\mathrm{M}-\mathrm{co}}{\mathrm{M} U} \frac{\mathrm{U}-\mathrm{co}}{\mathrm{M} U} \frac{\mathrm{NTC}}{\mathrm{M} U} \frac{\mathrm{Cl}}{\mathrm{M} U} \frac{\mathrm{C} 2}{\mathrm{M} U} \frac{\mathrm{C} 3}{\mathrm{M} U} \frac{\mathrm{C} 4}{\mathrm{M} U} \frac{\mathrm{C} 5}{\mathrm{M} U}
$$

\begin{tabular}{|c|c|c|c|c|c|c|c|c|c|c|c|c|c|c|c|}
\hline \multirow[t]{3}{*}{$D A P K 1-\mathrm{M} 2$} & \multicolumn{6}{|c|}{ 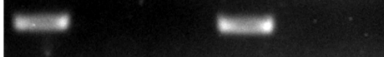 } & \multicolumn{2}{|c|}{-0} & \multicolumn{4}{|c|}{$-x=0$} & \multicolumn{3}{|c|}{-} \\
\hline & & & & & $N^{\prime}$ & & & & & & & N3 & & J4 & N5 \\
\hline & $\mathrm{M}$ & $\mathrm{U}$ & M & U & $\mathrm{M}$ & U & M & U & M & U & M & U & M & U & M \\
\hline$D A P K 1-\mathrm{M} 2$ & 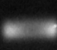 & & & $\mathrm{cos}$ & & & & $=$ & & 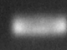 & & 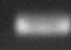 & & 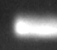 & $=$ \\
\hline
\end{tabular}

(D)

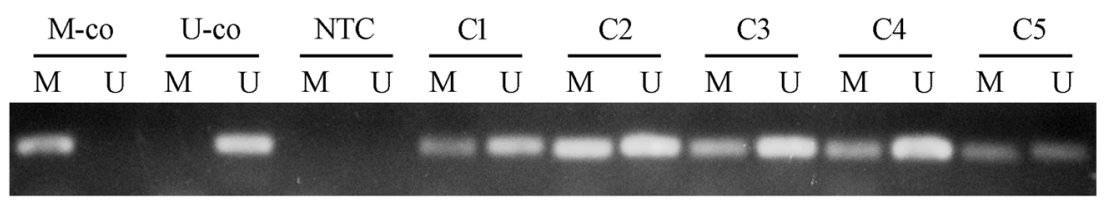

DAPK1-M3

$$
\frac{\mathrm{M}-\mathrm{co}}{\mathrm{M} U} \frac{\mathrm{U}-\mathrm{co}}{\mathrm{M} U} \frac{\mathrm{NTC}}{\mathrm{M} U} \frac{\mathrm{N} 1}{\mathrm{M} U} \frac{\mathrm{N} 2}{\mathrm{M} U} \frac{\mathrm{N} 3}{\mathrm{M}} \mathrm{U} \frac{\mathrm{N} 4}{\mathrm{M}} \mathrm{U} \frac{\mathrm{N} 5}{\mathrm{M} U}
$$

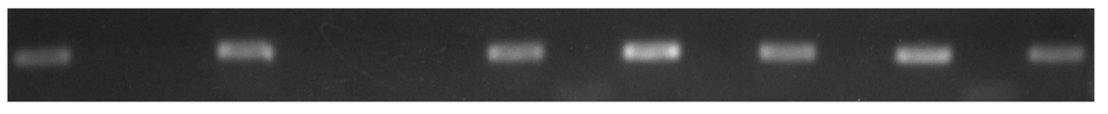

DAPK1-M3

(E)

$$
\frac{\mathrm{M}-\mathrm{co}}{\mathrm{M} U} \frac{\mathrm{U}-\mathrm{co}}{\mathrm{M} U} \frac{\mathrm{NTC}}{\mathrm{M} U} \frac{\mathrm{C} 1}{\mathrm{M} U} \frac{\mathrm{C} 2}{\mathrm{M} U} \frac{\mathrm{C} 3}{\mathrm{M} U} \frac{\mathrm{C} 4}{\mathrm{M} U} \frac{\mathrm{C} 5}{\mathrm{M} U}
$$

JAM3-M4

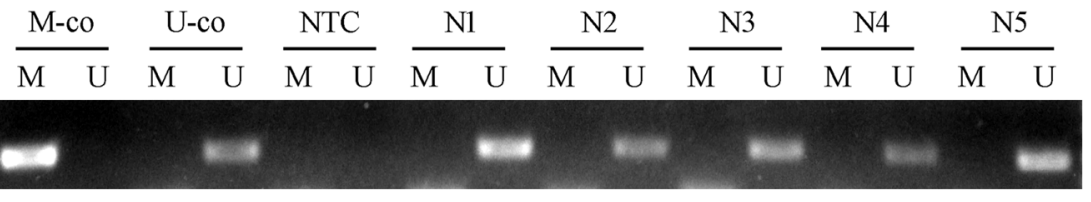

Figure 1: Methylation status of candidate genes in representative examples. (A) CADM1-M2. (B) CADM1-M8. (C) DAPK1-M2. (D) DAPK1-M3. (E) JAM3-M4. Abbreviations: C: cervical cancer. N: normal cervical tissue. M-co: bisulfite-converted methylated DNA. U-co: bisulfite-converted unmethylated DNA. NTC: no-template control. M: methylated-specific primer sets; U: unmethylated-specific primer sets. 
Table 3: Methylation frequency in tissue specimen obtained from patients with normal cervix or cervical cancer

\begin{tabular}{|l|c|c|c|}
\hline \multicolumn{1}{c|}{ Gene-locus } & Cancer & Normal & $P^{\mathbf{a}}$ \\
\hline CADM1-M2 & $28 / 43$ & $6 / 27$ & $<0.001$ \\
\hline CADM1-M8 & $32 / 43$ & $0 / 27$ & $<0.001$ \\
\hline DAPK1-M2 & $30 / 43$ & $3 / 27$ & $<0.001$ \\
\hline$D A P K 1-\mathrm{M} 3$ & $33 / 43$ & $2 / 27$ & $<0.001$ \\
\hline JAM3-M4 & $37 / 43$ & $2 / 27$ & $<0.001$ \\
\hline
\end{tabular}

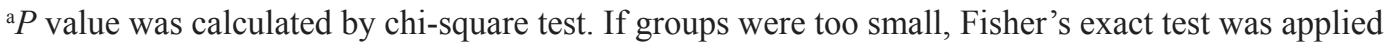

QMSP of $J A M 3-M 4$ as a triage marker in patients with abnormal cytology smear results and hrHPV-positive patients

With JAM3-M4 used as a triage marker for patients with abnormal cytology smear results (the cutoff was $\geq$ atypical squamous cells of unknown significance [ASCUS]), the AUC values were $0.911,0.843$ and 0.810 and $0.890,0.840$ and 0.795 for CIN3+/CIN1-, CIN3+/ CIN2- and CIN2+/CIN1- classifications in P1 and P2, respectively (Figures 3B, 4B). The sensitivity was slightly decreased and the specificity increased as compared with the triage performance of hrHPV, especially for the CIN3+/CIN1- and CIN3+/CIN2- classifications (Supplementary Table 2). The positive predictive value (PPV) and negative predictive value (NPV) were both increased for all classifications (Supplementary Table 2).

We divided patients with abnormal cytology results into ASCUS and low-grade squamous intraepithelial lesion (LSIL) subgroups and compared the diagnostic performance of JAM3-M4 to the triage performance of hrHPV testing (Figures 3C, 4C, 3D, 4D, Tables 4 and 5). For both ASCUS and LSIL subgroups, the specificity and PPV of JAM3-M4 was increased significantly for all classification groups, at the cost of a moderate decrease in sensitivity and NPV for ASCUS patients (Tables 4 and 5).
(A)

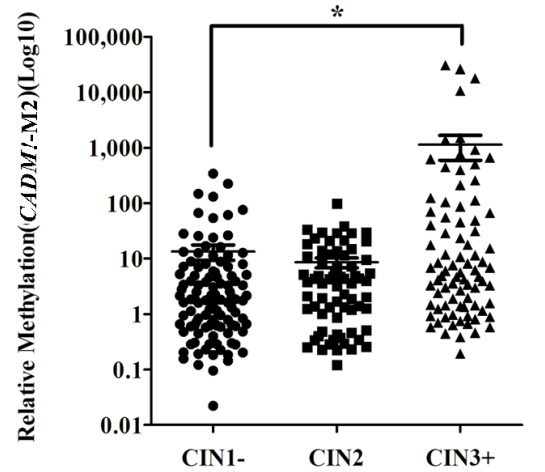

(C)

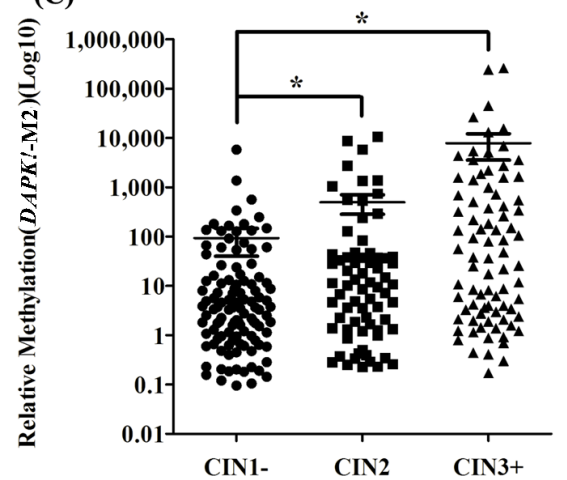

(B)

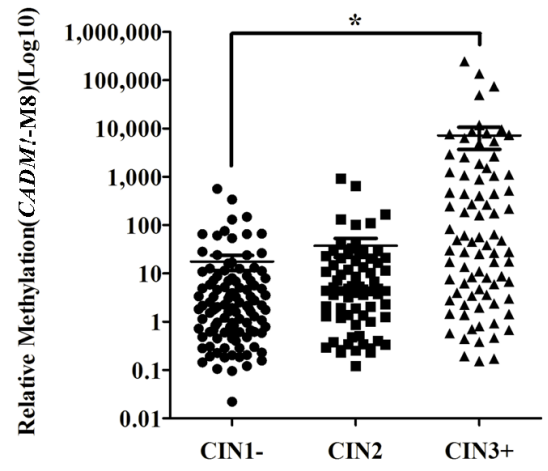

(D)

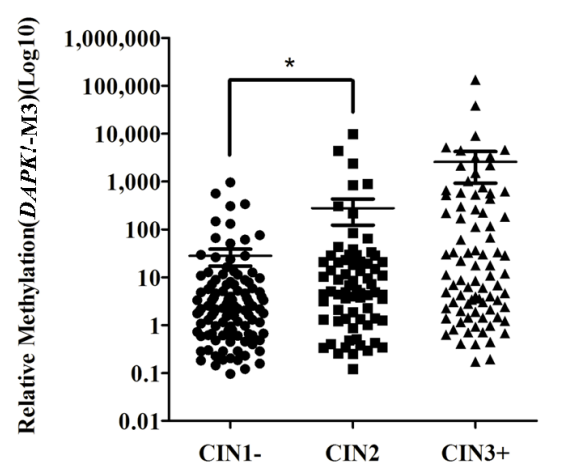

(E)

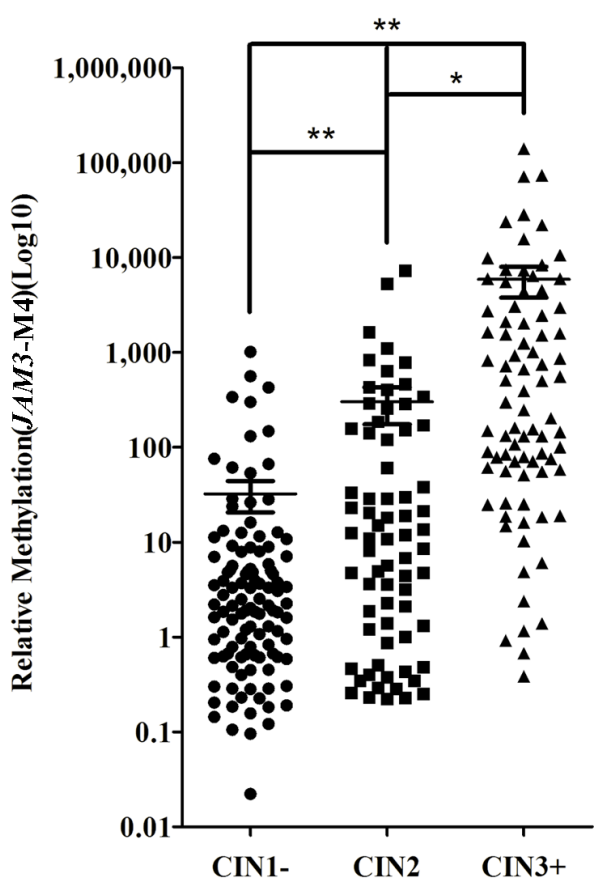

Figure 2: Methylation ratio in cervical scrapings from patients referred for colposcopy $(\boldsymbol{n}=\mathbf{2 6 7})$. Dot plots illustrate the methylation ratio distributions. Methylation ratio of (A) CADM1-M2, (B) CADM1-M8, (C) DAPK1-M2, (D) DAPK1-M3, (E) JAM3-M4. CIN1-: no neoplasia and CIN1. CIN3+: CIN3 and cancer cases. ${ }^{*} P<0.05, * * P<0.01$. Each point represents one sample; the horizontal line is the mean and whiskers are SEM. 
Patients with ASCUS who were $<30$ years old $(n=19)$ were all hrHPV-positive; 15 had CIN1-, all negative for the JAM3-M4 marker.

With JAM3-M4 used as a triage marker for hrHPVpositive patients, the AUC was $0.904,0.846$ and 0.771 and $0.871,0.848$ and 0.711 for $\mathrm{CIN} 3+/ \mathrm{CIN} 1-, \mathrm{CIN} 3+/ \mathrm{CIN} 2-$
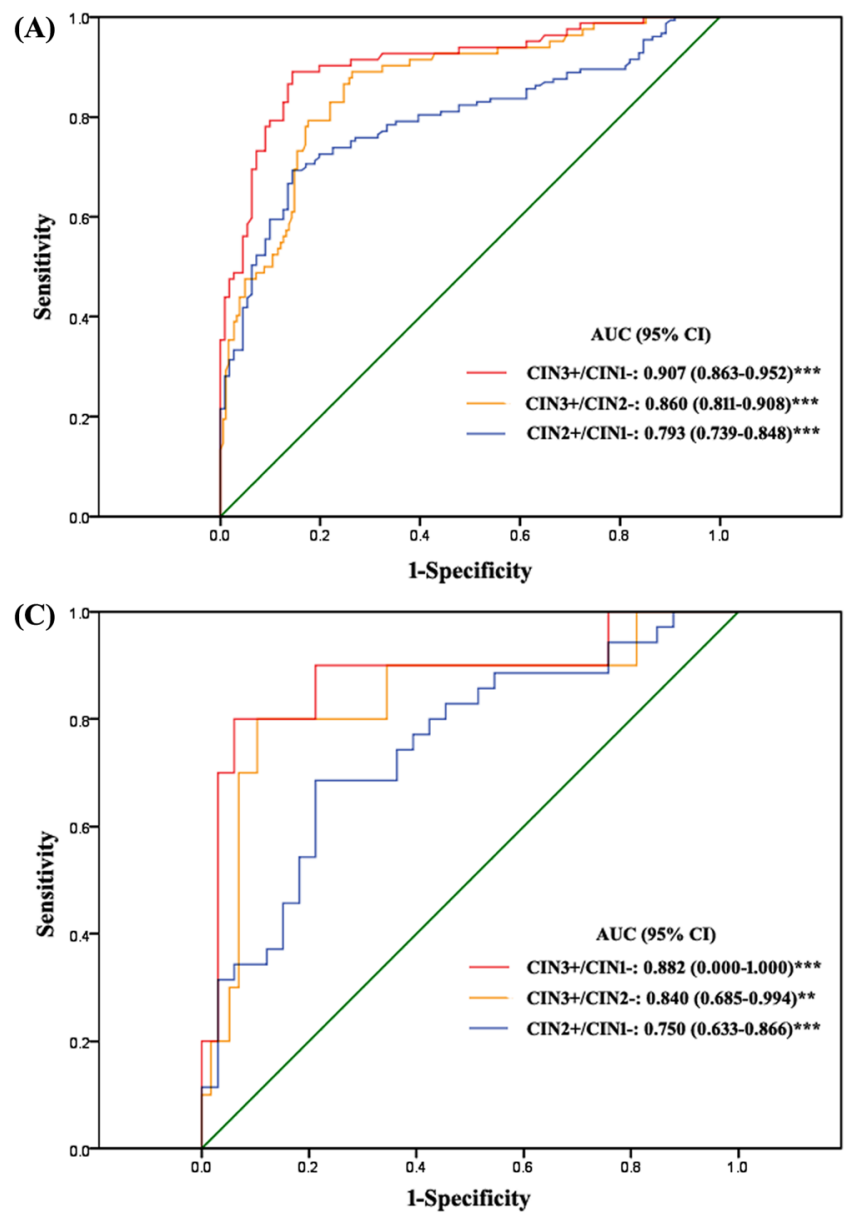

and CIN2+/CIN1- classifications in P1 and P2, respectively (Figures 3E, 4E). JAM3-M4 showed slightly decreased sensitivity, with increased specificity, PPV, and NPV as compared with triage performance of cytology testing, especially for CIN3+/CIN1- and CIN3+/CIN2classifications (Tables 4 and 5).
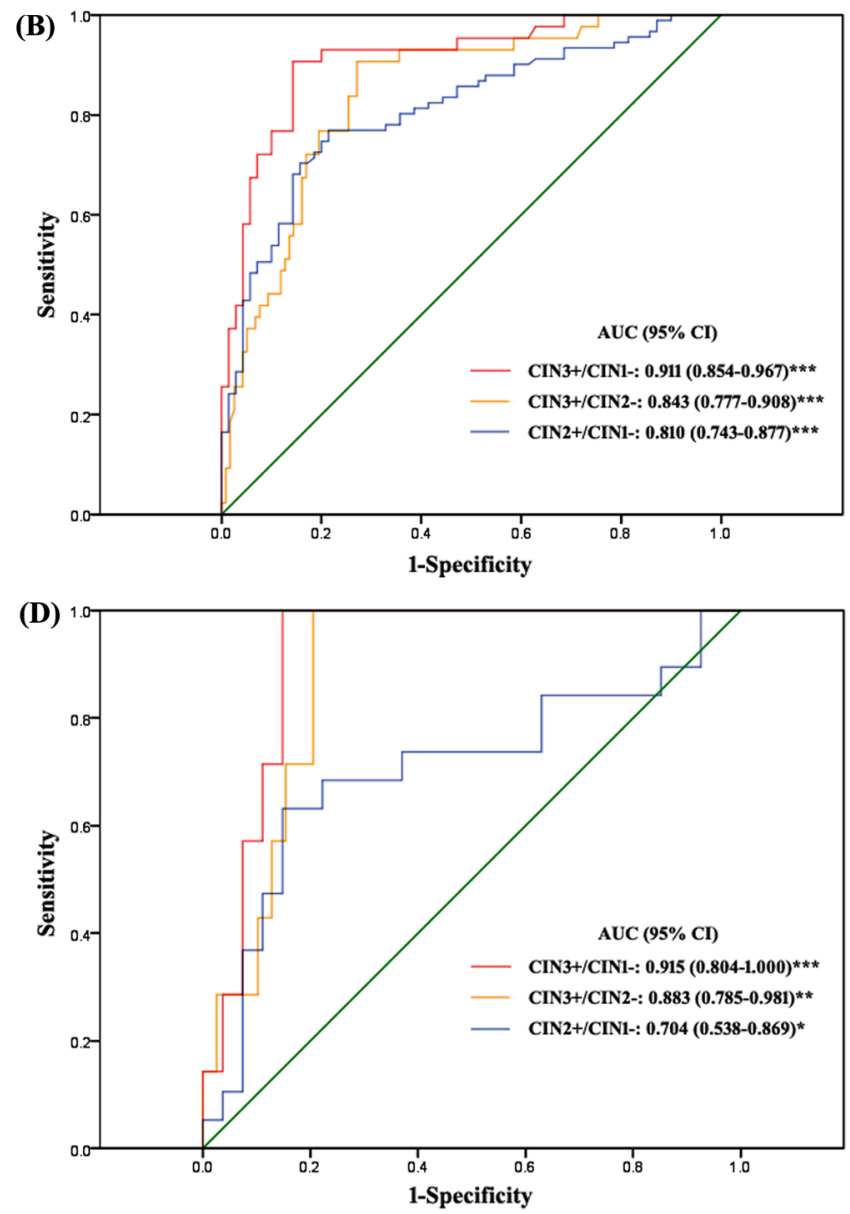

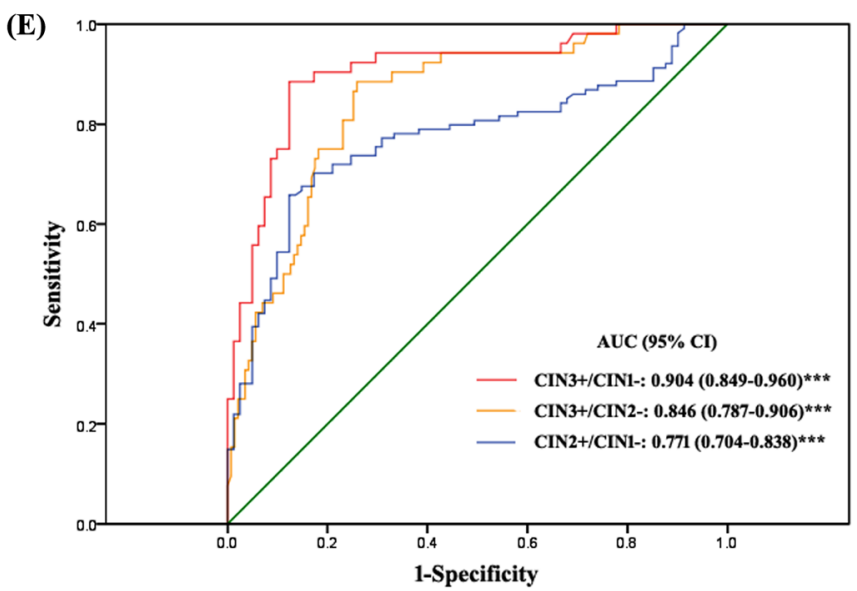

Figure 3: Receiver operating characteristic (ROC) curves of the discriminating performance of $J A M 3-M 4$ in different classifications of diagnostic groups in P1. The area under the ROC curve (AUC) was used to estimate accuracy. JAM3-M4 performance for (A) all patients, (B) patients with abnormal cytology result, (C) patients with atypical squamous cells of unknown significance (ASCUS), (D) patients with low-grade squamous intraepithelial lesion (LSIL), (E) patients positive for high-risk human papillomavirus (hrHPV-positive). ${ }^{*} P<0.05, * * P<0.01, * * * P<0.001 ; 95 \% \mathrm{CI}, 95 \%$ confidence interval. 
Table 4: Triage performance of methylation marker for patients with hrHPV positive and patients with cytology result of ASCUS and LSIL in P1

\begin{tabular}{|c|c|c|c|c|c|c|c|c|c|c|c|c|}
\hline & \multicolumn{4}{|c|}{ CIN3+/CIN1- } & \multicolumn{4}{|c|}{ CIN3+/CIN2- } & \multicolumn{4}{|c|}{ CIN2+/CIN1- } \\
\hline & $\begin{array}{l}\text { SEN } \\
(\%)\end{array}$ & $\begin{array}{l}\text { SPE } \\
(\%)\end{array}$ & $\begin{array}{l}\text { PPV } \\
(\%)\end{array}$ & $\begin{array}{c}\text { NPV } \\
(\%)\end{array}$ & $\begin{array}{l}\text { SEN } \\
(\%)\end{array}$ & $\begin{array}{l}\text { SPE } \\
(\%)\end{array}$ & $\begin{array}{l}\text { PPV } \\
(\%)\end{array}$ & $\begin{array}{l}\text { NPV } \\
(\%)\end{array}$ & $\begin{array}{l}\text { SEN } \\
(\%)\end{array}$ & $\begin{array}{l}\text { SPE } \\
(\%)\end{array}$ & $\begin{array}{l}\text { PPV } \\
(\%)\end{array}$ & $\begin{array}{l}\text { NPV } \\
(\%)\end{array}$ \\
\hline ASCUS $\rightarrow \mathrm{HPV}$ & 100.00 & 21.88 & 26.47 & 100.00 & 100.00 & 12.50 & 15.52 & 100.00 & 100.00 & 21.88 & 56.90 & 100.00 \\
\hline ASCUS $\rightarrow J A M 3-\mathrm{M} 4$ & 72.73 & 81.82 & 57.14 & 90.00 & 72.73 & 70.69 & 32.00 & 93.18 & 52.78 & 81.82 & 76.00 & 61.36 \\
\hline LSIL $\rightarrow \mathrm{HPV}$ & 100.00 & 15.38 & 18.52 & 100.00 & 100.00 & 10.81 & 13.16 & 100.00 & 100.00 & 15.38 & 42.10 & 100.00 \\
\hline LSIL $\rightarrow$ JAM3-M4 & 100.00 & 85.18 & 63.64 & 100.00 & 100.00 & 80.00 & 46.67 & 100.00 & 63.16 & 85.18 & 75.00 & 76.67 \\
\hline $\mathrm{HPV}(+) \rightarrow$ Cytology & 91.67 & 30.67 & 38.82 & 88.46 & 91.67 & 25.58 & 25.58 & 91.67 & 85.56 & 30.67 & 59.69 & 63.89 \\
\hline $\mathrm{HPV}(+) \rightarrow J A M 3-\mathrm{M} 4$ & 86.79 & 87.65 & 82.14 & 91.02 & 86.79 & 73.43 & 54.76 & 93.75 & 65.22 & 87.65 & 88.24 & 63.96 \\
\hline
\end{tabular}

Table 5: Triage performance of methylation marker for patients with hrHPV positive and patients with cytology result of ASCUS and LSIL in P2

\begin{tabular}{|c|c|c|c|c|c|c|c|c|c|c|c|c|}
\hline & \multicolumn{4}{|c|}{ CIN3+/CIN1- } & \multicolumn{4}{|c|}{ CIN3+/CIN2- } & \multicolumn{4}{|c|}{ CIN2+/CIN1- } \\
\hline & $\begin{array}{l}\text { SEN } \\
(\%)\end{array}$ & $\begin{array}{l}\text { SPE } \\
(\%)\end{array}$ & $\begin{array}{l}\text { PPV } \\
(\%)\end{array}$ & $\begin{array}{l}\text { NPV } \\
(\%)\end{array}$ & $\begin{array}{l}\text { SEN } \\
(\%)\end{array}$ & $\begin{array}{l}\text { SPE } \\
(\%)\end{array}$ & $\begin{array}{c}\text { PPV } \\
(\%)\end{array}$ & $\begin{array}{c}\text { NPV } \\
(\%)\end{array}$ & $\begin{array}{l}\text { SEN } \\
(\%)\end{array}$ & $\begin{array}{l}\text { SPE } \\
(\%)\end{array}$ & $\begin{array}{l}\text { PPV } \\
(\%)\end{array}$ & $\begin{array}{l}\text { NPV } \\
(\%)\end{array}$ \\
\hline ASCUS $\rightarrow \mathrm{HPV}$ & 100.00 & 11.36 & 18.75 & 100.00 & 100.00 & 7.81 & 13.24 & 100.00 & 100.00 & 11.36 & 42.65 & 100.00 \\
\hline ASCUS - & 70.00 & 90.38 & 58.33 & 94.00 & 70.00 & 81.94 & 5.00 & 95.16 & 50.00 & 90.38 & 75.00 & 75.81 \\
\hline LSIL $\rightarrow \mathrm{HPV}^{*}$ & 100.00 & 0.00 & 28.57 & - & 100.00 & 0.00 & 25.00 & - & 100.00 & 0.00 & 37.50 & - \\
\hline $\mathrm{LSIL} \rightarrow J A M 3-\mathrm{M} 4$ & 100.00 & 78.57 & 70.00 & 100.00 & 100.00 & 71.43 & 53.85 & 100.00 & 71.43 & 78.57 & 76.92 & 73.33 \\
\hline HPV $(+) \rightarrow$ Cytology & 78.57 & 43.96 & 30.14 & 86.96 & 78.57 & 38.58 & 22.00 & 89.09 & 76.56 & 43.96 & 49.00 & 72.73 \\
\hline $\mathrm{HPV}(+) \rightarrow J A M 3-\mathrm{M} 4$ & 80.64 & 89.58 & 71.43 & 93.48 & 80.64 & 80.29 & 48.08 & 94.83 & 58.33 & 89.58 & 80.77 & 74.14 \\
\hline
\end{tabular}

*All the patients with cytology result of LSIL were hrHPV positive.

\section{QMSP of $J A M 3-M 4$ as a complementary marker in cytology or hrHPV testing}

With JAM3-M4 used as a complementary marker in hrHPV or cytology testing, the sensitivity was slightly lower and the specificity and PPV was increased greatly as compared with the combination of cytology and hrHPV testing in P1 (Supplementary Table 3). As most likely used in clinical practice, JAM3-M4 as a complementary marker in cytology testing was further confirmed in P2 (Supplementary Table 4).

\section{Pyrosequencing validation of the methylation status of JAM3-M4}

Methylation levels across the $\mathrm{CpG}$ sites for JAM3-M4 were relatively stable. The mean methylation ratio of the 5 representative $\mathrm{CpG}$ sites was $4.94 \pm 1.20$, $4.36 \pm 2.30,5.37 \pm 1.57,10.68 \pm 6.08,18.49 \pm 16.91$ and $52.70 \pm 14.71$ for the patient groups: negative for intraepithelial lesion and malignancy (NILM) $(n=8)$, CIN1 $(n=10)$, CIN2 QMSP-negative $(\mathrm{QM}(-))(n=9)$,
CIN2 QM $(+)(n=8)$, CIN3 $(n=10)$ and cancer $(n=9)$ (Figure 5A). The mean methylation ratio of corresponding specimens detected by QMSP and pyrosequencing did not differ (data not shown). Pyrosequencing revealed significant differences between CIN2 QM(-) and CIN2 $\mathrm{QM}(+), \mathrm{CIN} 3$ and cancer (Figure 5B).

To be consistent with the QMSP analysis of the loci, we examined $J A M 3-\mathrm{M} 4$ discrimination among relevant diagnostic groups (CIN1-, CIN2, CIN3+) and found that it was significantly discriminative (Figure $5 \mathrm{C}$ ).

\section{Discriminating performance of $J A M 3-M 4$ for CIN2 patients}

Immunohistochemistry analysis of P16 and the corresponding pyrosequencing analysis in samples from representative CIN2 patients are in Figure 6. The rate of positive staining for P16 was $69.9 \%$ and the rate of positive methylation for JAM3-M4 was $48.8 \%$. The methylation ratio for JAM3-M4 between LSIL and HSIL was significant $(P=0.03)$. The coincidence rate was $60.5 \%(P=0.119)$. 


\section{DISCUSSION}

We used both cervical tissue specimens and cervical scrapings for an in-depth analysis of the methylation status of different loci in candidate gene promoters and their possible
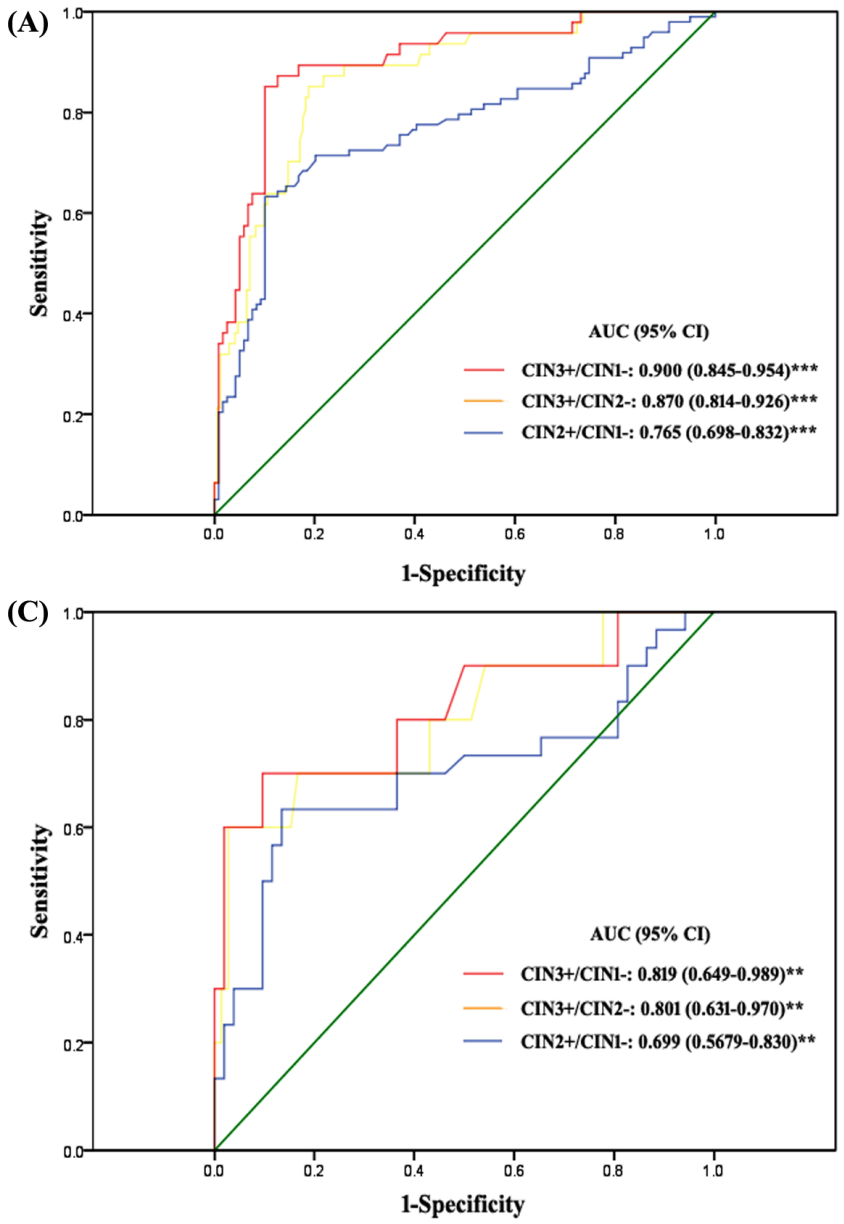

diagnostic relevance in cervical neoplasia. JAM3-M4 showed good performance in two different and independent studies (P1 and $\mathrm{P} 2)$ but also with three different diagnostic classifications. JAM3-M4 methylation may be a marker for triage and a complementary marker in clinical practice.

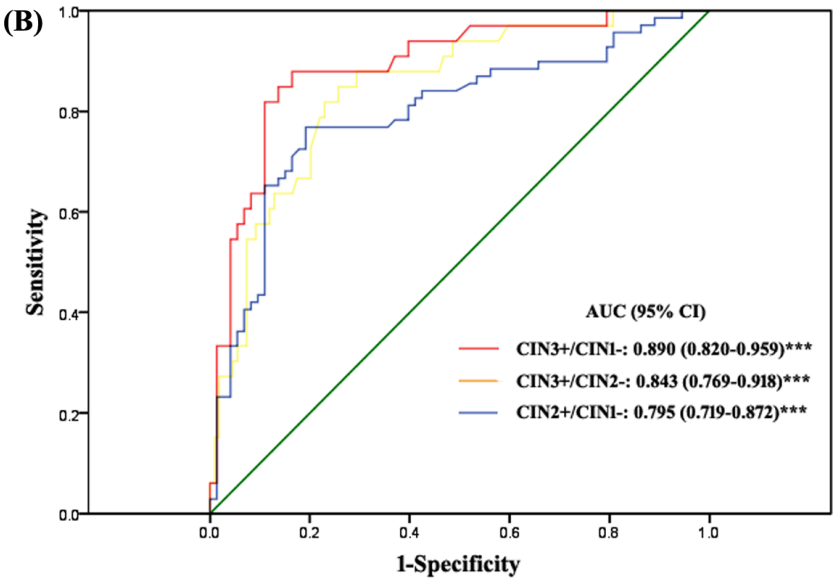

(D)

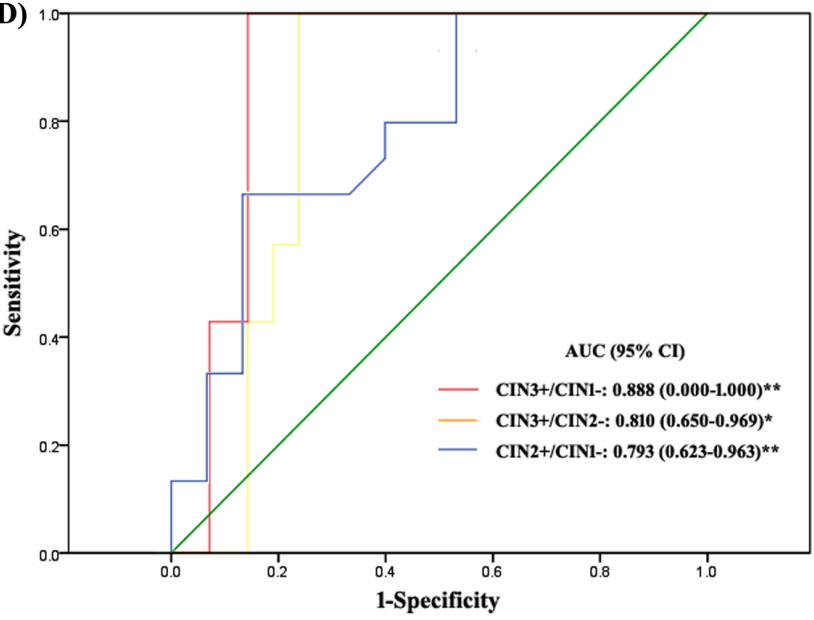

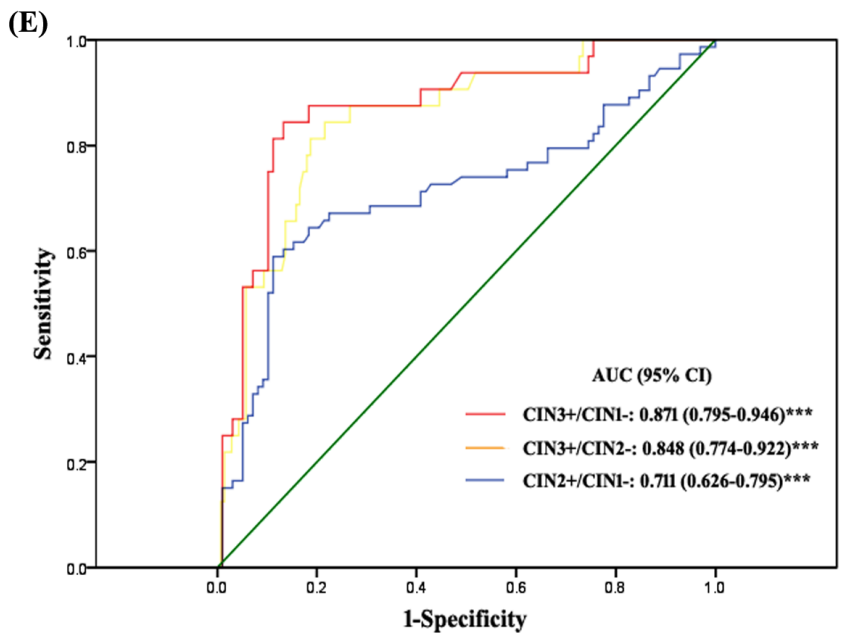

Figure 4: ROC curves of the discriminating performance of $J A M 3-M 4$ in different classifications of diagnostic groups in P2. The area under the ROC curve (AUC) was used to estimate accuracy. JAM3-M4 performance for (A) all patients, (B) patients with abnormal cytology result, (C) patients with atypical squamous cells of unknown significance (ASCUS), (D) patients with low-grade squamous intraepithelial lesion (LSIL), (E) patients positive for high-risk human papillomavirus (hrHPV-positive). $* P<0.05, * * P<0.01$, $* * * P<0.001 ; 95 \% \mathrm{CI}, 95 \%$ confidence interval. 
Detecting and identifying cervical preneoplasia is important to halt the progression to cancer. As a promising methylation marker, JAM3 has been investigated for discriminating performance $[12,13,30,31]$. However, the studies investigated the same locus in different media, including conventional liquid-based

(A)
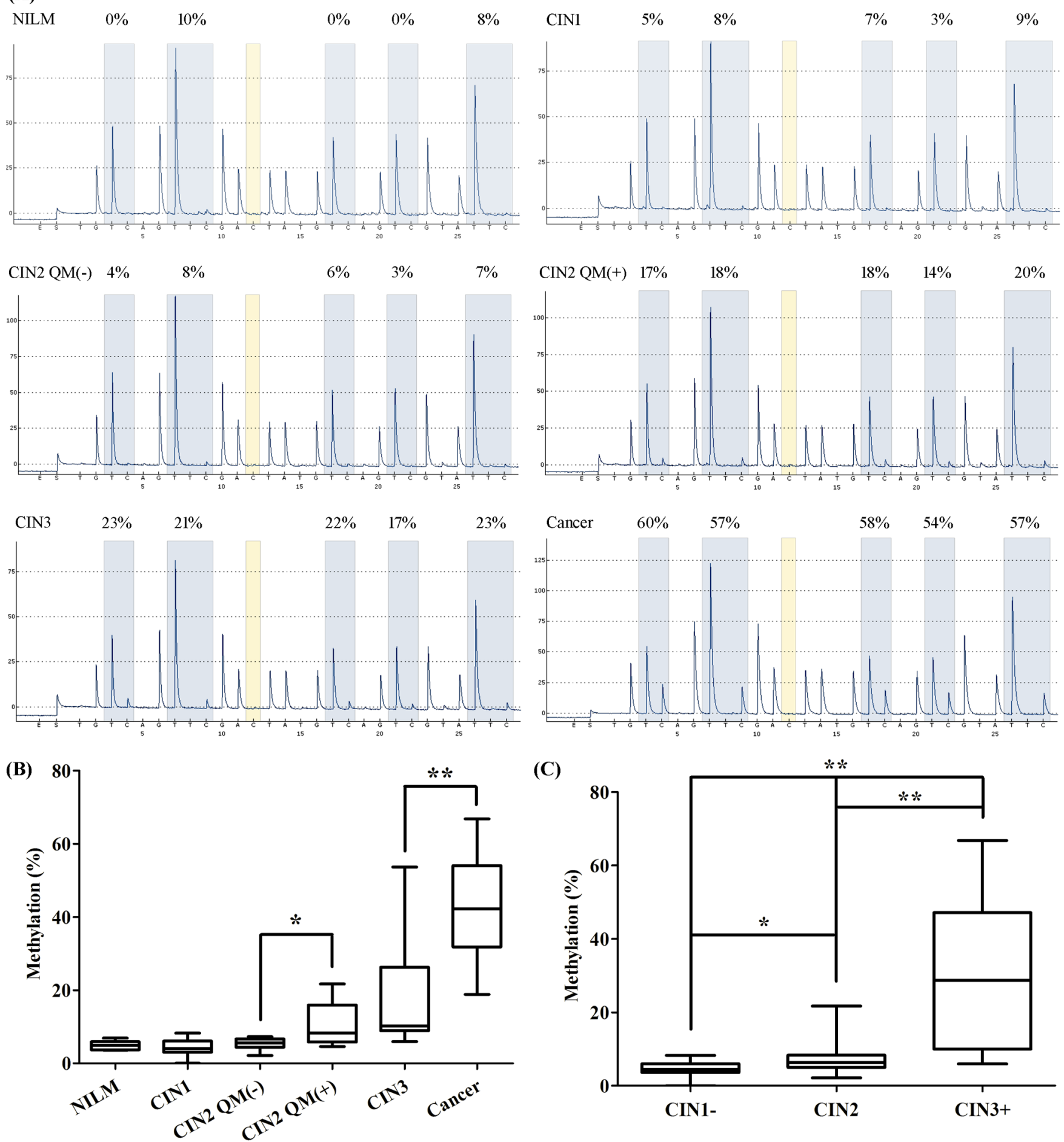

Figure 5: Pyrosequencing analysis of representative loci in $\boldsymbol{J}$ AM3-M4. (A) Methylation status of representive loci in representative samples from patient groups: negative for intraepithelial lesion and malignancy (NILM), cervical intraepithelial neoplasia 1 (CIN1), CIN2 QMSP-negative $[\mathrm{QM}(-)], \mathrm{CIN} 2 \mathrm{QM}(+), \mathrm{CIN} 3$, and cancer confirmed by pyrosequencing. (B) Box-plot of the methylation percentage for JAM3-M4 for loci for the 6 groups, with statistical analysis between every 2 neighbouring groups. (C) Box-plot of the methylation percentage for JAM3-M4 for loci for diagnostic groups (CIN1-, CIN2, CIN3+) consistent with the QMSP analysis. Horizontal line is median, whiskers are 5th and 95th percentiles, and lower and upper box boundaries are 25th and 75 th percentiles. ${ }^{*} P<0.05$, $* * P<0.01$. 
cytology, self-sampled brush material and cervico-vaginal lavage. We compared several loci of the same gene and found a new locus, JAM3-M4, with promising predictive power in primary screening of cervical neoplasia. We also investigated its combined application with the most widely used screening methods - hrHPV and cytology-based Pap smear testing.

Infection with HPV causes cervical preneoplasia and neoplasia [32]. Depending on the hrHPV testing, the diagnosis can cause over-diagnosis and over-treatment. Unnecessary referral to the gynecologist leads to anxiety, distress [33], and even anger and resentment with a perceived threat to life and/or fertility [34]. Compared to the widely used triage test-cytology after hrHPV testing -JAM3-M4 showed increased specificity and PPV. Thus, most unnecessary referrals for colposcopy could be avoided. In addition, with the acceptable PPV of JAM3-M4, hrHPV-positive patients also positive for JAM3-M4 could be directly referred to colposcopy.

Considering cost-effectiveness, long-term application and high specificity for serious lesions, cytomorphological appraisal is still widely used as primary screening. Developing countries lack quality-controlled cytology testing, and the diagnostic performance is unsatisfactory. The addition of a methylation marker could improve the predictive power even better than combined with HPV testing. Considering the low sensitivity of cytology testing in population-based screening, use of JAM3-M4 could be complementary to cytology testing to improve performance, especially the specificity and PPV.

Patients with ASCUS or LSIL account for a considerable proportion of biopsy-confirmed CIN2+ cases [35]. However, the underlying risk of ASCUS or LSIL progressing to CIN2+ is still quite low, from $4 \%$ to $8 \%$ for ASCUS and $12 \%$ to $15 \%$ for LSIL [36].
The most widely adopted triage strategy for ASCUS is hrHPV testing. For young patients $(<30$ years old), because of the high prevalence of HPV, the test is less effective [37]. As well, because of the high HPV infection rates of LSIL patients $-77 \%$ [38] to $80 \% \sim 85 \%$ [39] - such patients need alternative triage methods.

We investigated the potential of using JAM3-M4 in triage of patients with ASCUS and LSIL. Both the specificity and PPV were increased as compared with hrHPV. JAM3-M4 could be especially used as a triage marker for patients $<30$ years old in light of the less effective triage performance of hrHPV testing in such patients. For LSIL patients, JAM3-M4 is ideal as a triage marker without loss of sensitivity and NPV. A proposed scheme for application of this methylation marker in triage is in Figure 7.

CIN lesions are divided into productive (CIN1 and CIN2) and transforming (CIN2 and CIN3) lesions. Productive CIN2 cannot be distinguished from transforming CIN2 by morphology assessment alone [23]. In our study, JAM3-M4 performed better with the CIN3+/ CIN1- than CIN3+/CIN2- classification. Therefore, the methylation status of CIN2 is also mixed. At present, we lack a well-recognized gold standard to distinguish mixed CIN2. The updated guidelines [40] from the World Health Organization recommend immunohistochemistry analysis of P16 in biopsies to distinguish CIN2 as LSIL or HSIL. Therefore, we compared JAM3-M4 methylation status with P16 staining in CIN2 patients. Although results were not statistically significant, JAM3-M4 methylation status was still helpful for differentiating LSIL and HSIL.

Because the JAM3 methylation marker we identified is specific to cervical cancer and discriminative among all diagnostic groups, the role of this gene in carcinogenesis is of interest. JAMs have been described as major

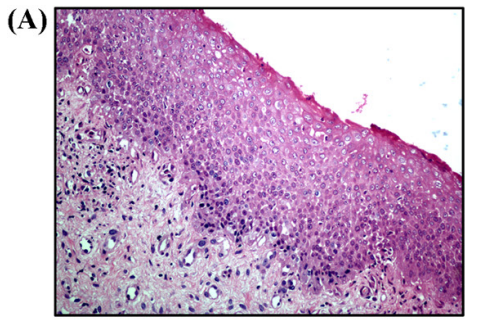

(B)

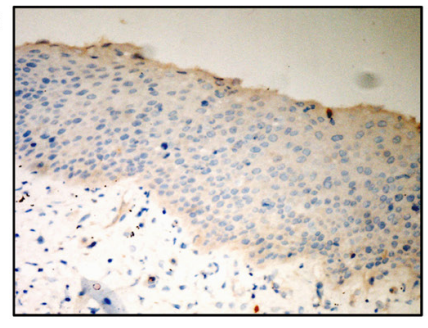

(D)

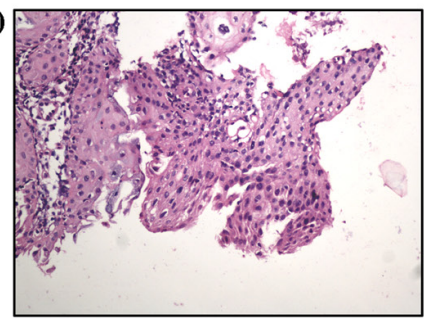

(E)

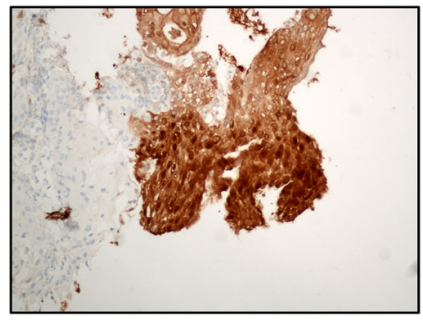

(C)

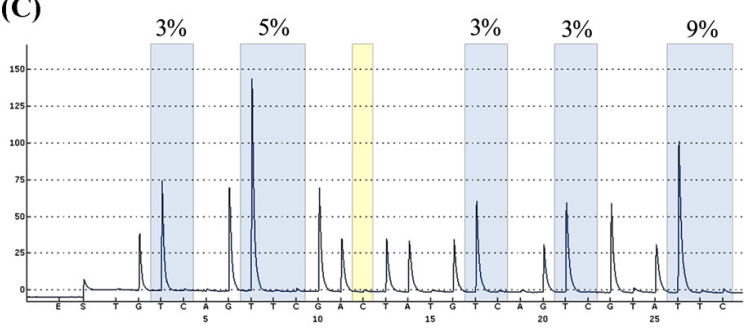

(F)

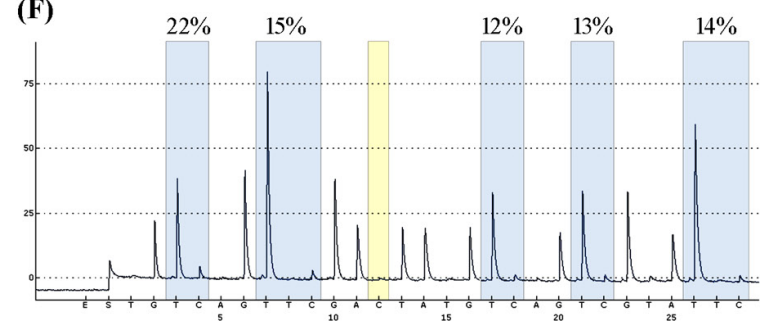

Figure 6: Immunohistochemical staining of P16 in samples from patients with histological diagnosis of CIN2. (A) Hematoxylin and eosin staining (H/E) for LSIL, and (B) P16, negative in LSIL tissue. (C) Pyrosequencing analysis of LSIL. (D) H/E staining of HSIL, and (E) P16, positive in HSIL tissue. (F) Pyrosequencing analysis of HSIL. Original magnification, A, B, C, D, $\times 200$. 
components of tight junctions pivotal for establishing and maintaining cell polarity in endothelial and epithelial cells [41, 42]. During tumor development, they are remodeled, thereby allowing neoplastic cells to escape from constraints imposed by intercellular junctions and activate the cytoskeleton machinery into a pro-migratory state of the cell. Overexpression of JAM3 in an epithelial carcinoma cell line improved tight junctions and restored an epithelial phenotype [43], and the expression was downregulated in gastric adenocarcinoma tissue [44]. JAM3 promoted hematogenous lung metastasis in melanoma [45] and in an experimental metastatic model in vivo [46]. Therefore, its expression and participation vary in tumor cell-endothelial cell interactions in different tumor cells and the specific role in cervical carcinogenesis has not been studied. Investigating the role of JAM3 in cervical carcinogenesis and whether and which role methylation may play in it would be of interest.
Our study contains some limitations. We examined methylation status in cervical scrapings from patients with a biopsy due to colposcopic abnormalities to avoid verification bias. This cohort was highly selected and was not representative of a screening population. Therefore, this marker may perform differently in a general population of asymptomatic women. Besides squamous cell carcinoma, other clinically important histological variants of cervical cancer, such as adenocarcinoma, exist. We have collected some but not many cervical scrapings of reactive or dysplastic glandular lesion in the cervix. However, JAM3-M4 will be further investigated if enough samples are available and may be found a biomarker.

Our study suggests that the JAM3-M4 methylation marker may be used as a triage marker for hrHPVpositive patients. For cytology testing, it is also an objective complementary marker, and its detection can be an effective triage strategy for patients with

(A)

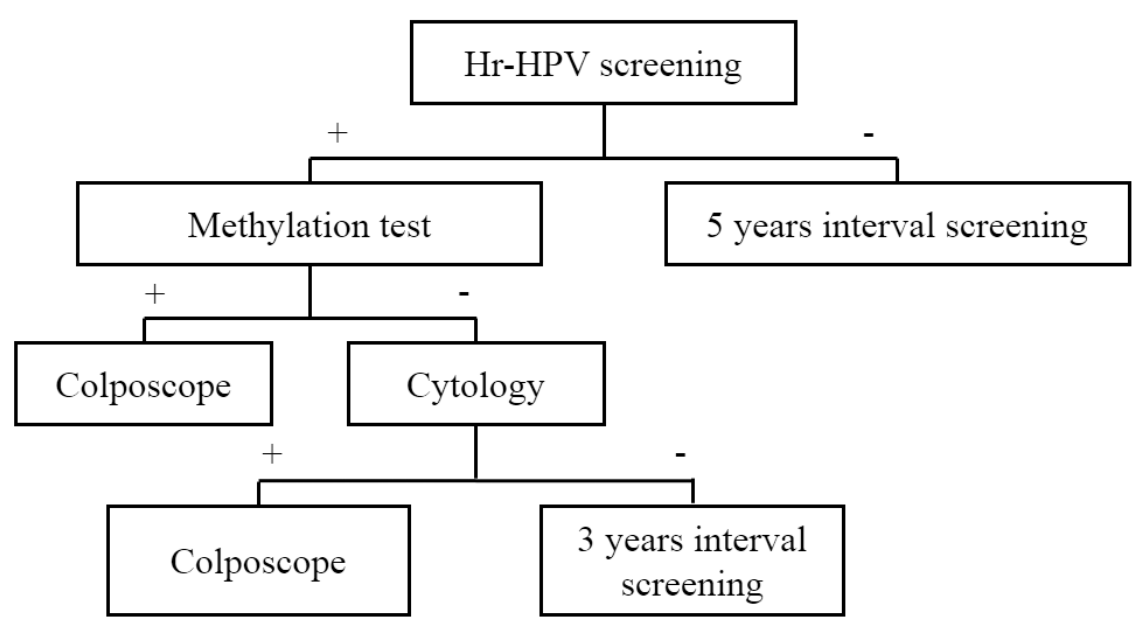

(B)

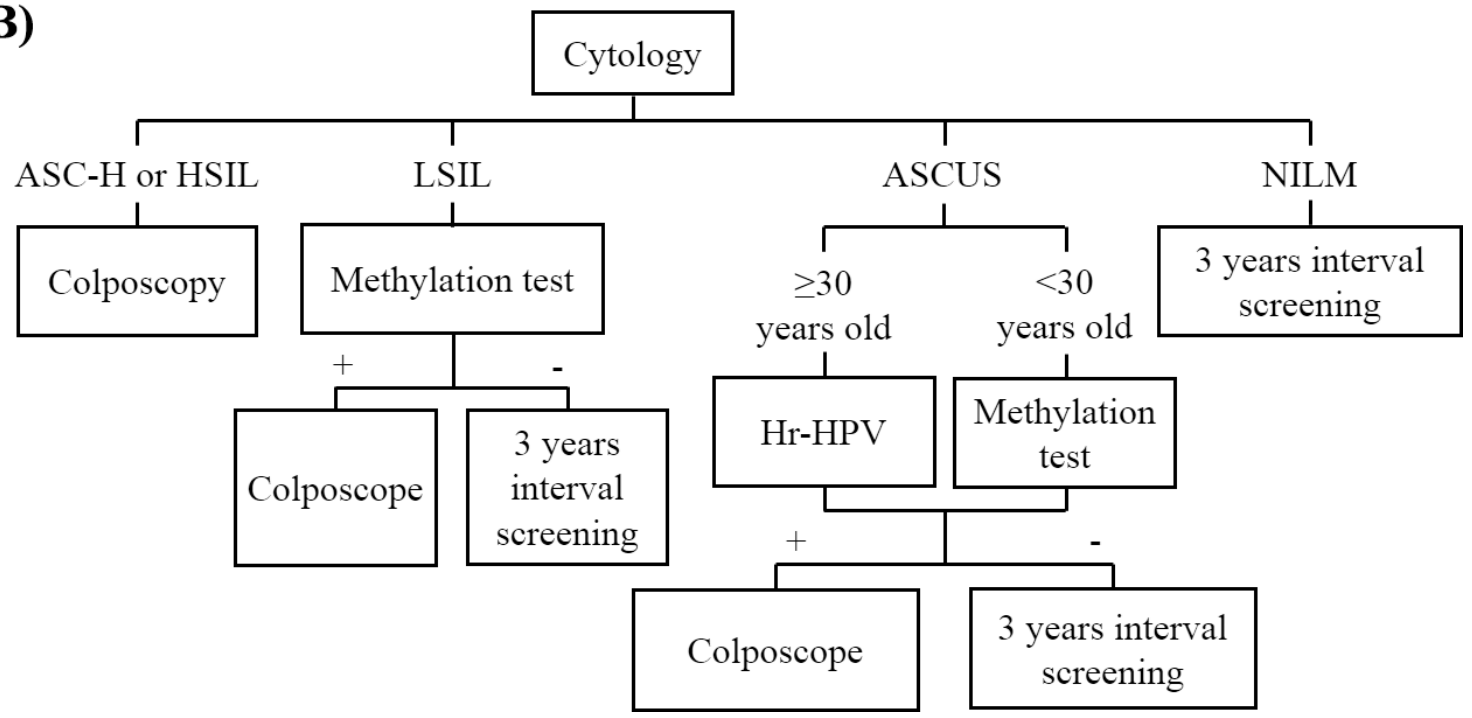

Figure 7: Possible scenarios for the incorporation of a methylation test with $J A M 3-M 4$ in cervical cancer screening as a triage marker in (A) HrHPV testing or (B) cytology testing. 
ASCUS, especially those who are $<30$ years old and those with LSIL. The performance of this marker should be further evaluated in a prospective, population-based study.

\section{MATERIALS AND METHODS}

\section{Ethics statement}

The investigation was conducted in accordance with the ethical standards and according to the Declaration of Helsinki and national and international guidelines and was approved by the authors' institutional review board.

\section{Patients}

Frozen tissue specimens from 43 cervical cancer and 27 normal cervix were obtained from Qilu Hospital, Shandong University, from January to November 2013. Normal cervix tissue samples were obtained from patients without a history of abnormal cytology smears who planned to undergo hysterectomy for nonmalignant reasons, including fibroids, prolaps uteri, adenomyosis, hypermenorrhea or a combination of these. All cervical tissue was confirmed to be histopathologically normal.

QMSP analysis involved cervical scrapings taken under colposcopic guidance from February 2014 to January 2015 (P1) and July to September 2015 (P2). Samples were selected by random. The sample size was determined with respect to statistical calculation and feasibility and estimated on the basis of significance $\alpha$, power $1-\beta$ and data from preliminary experiments. Only tissue from patients with confirmed histological diagnosis was included. The exclusion criteria were patients with a history of cervical neoplasia, cervix surgery, genital warts, an immunocompromised state, the presence of other cancers, or pregnancy. Histological diagnosis was assessed by 2 qualified pathologists in a blinded fashion. Informed consent was obtained from all patients and controls participating in this study. This study was approved by the ethics committee of Qilu Hospital, Shandong University.

\section{Cytology testing and hrHPV testing}

Cervical smears were cytomorphologically assessed in Thinprep Preservcyt medium (Hologic Inc, USA) by 2 qualified pathologists in a blinded fashion according to the Bethesda nomenclature [47].

Infection with hrHPV was detected by using $\mathrm{HC} 2$ kits (Qiagen $\mathrm{GmbH}$, Germany). Samples with a relative light unit (RLU) ratio $>1.0$ were recorded as positive.

\section{DNA extraction and bisulfite modification}

Genomic DNA of frozen tissue and cervical scrapings was extracted by using the Q1Aamp DNA Mini Kit (Qiagen GmbH, Germany). Sodium bisulfate treatment of extracted genomic DNA involved use of EpiTect Bisulfite kits (Qiagen GmbH, Germany). The extracted DNA and modified DNA underwent PCR with primers for the house-keeping gene GAPDH (forward: AGGTCGGAGTCAACGGATTTG, reverse: GTGATGGCATGGACTGTGGT) and $\beta$-actin (forward: TGGTGATGGAGGAGGTTTAGTAAGT, reverse: AACCAATAAAACCTACTCCTCCCTTAA).

\section{Methylation-sensitive PCR (MSP) and quantitative MSP (QMSP)}

MSP was performed on modified genomic DNA. Each PCR was performed in a final volume of $20 \mu \mathrm{L}$ containing $5 \mu \mathrm{M}$ each primer, $1 \mu \mathrm{L}$ bisulfite-conversion DNA, and $1 \times$ AmpliTaq Gold 360 Master Mix (ABI, USA). A sample was considered methylationpositive when a PCR product of the right size was visible after 40 cycles of PCR. The primers are in Table 6.

QMSP involved $95^{\circ} \mathrm{C}$ for $10 \mathrm{~min}$, followed by 40 cycles at $95^{\circ} \mathrm{C}$ for $15 \mathrm{~s}, 58-60^{\circ} \mathrm{C}$ for $1 \mathrm{~min}$ in a total volume of $20 \mu \mathrm{L}$ based on the 7900HT Fast Real-Time PCR System (ABI, USA). The primers were identical to those for M markers used in MSP to evaluate the same locus of one gene. The final reaction mixture contained 50 nM each primer, $1 \times$ Power SYBR Green PCR Master Mix (ABI, USA), and $1 \mu \mathrm{L}$ bisulfite-converted genomic DNA. EpiTect Control DNA and Control DNA Sets (QIAGEN, Germany; containing both bisulfite-converted methylated and unmethylated DNA, and unconverted unmethylated DNA) were used as MSP and QMSP control DNA. In addition, PCR of the bisulfite converted housekeeping gene $\beta$-actin was performed as a reference.

Each sample was analyzed in triplicate. Cycle threshold $(\mathrm{Ct})$ ratios between the $\mathrm{Ct}$ values of the $\beta$-actin and target were used to quantify the level of methylation,

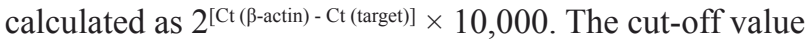
of QMSP for positivity/negativity was calculated and confirmed by receiver operating characteristic (ROC) analysis. Samples with $\mathrm{Ct}$ values for $\beta$-actin $>32$ were considered invalid and excluded from the analysis because they indicated poor DNA quality or recovery after bisulfite treatment.

\section{Pyrosequencing}

Randomly selected samples of different groups underwent pyrosequencing to detect representative loci of JAM3-M4 with use of the PyroMark MD system (Qiagen $\mathrm{GmbH}$, Germany) and the frequency of $\mathrm{CpG}$ methylation was measured by using PyroMark $\mathrm{CpG}$ software.

\section{Immunohistochemistry}

Sections (cervix scrapings and biopsy both collected during colposcopy) from patients histologically confirmed 
Table 6: MSP and QMSP primers

\begin{tabular}{|c|c|c|c|c|}
\hline Gene (locus) & Forward $5^{\prime}-3^{\prime}$ & Reverse 5'-3' & $\begin{array}{c}\text { Fragment } \\
\text { size (bp) }\end{array}$ & $\operatorname{Tm}\left({ }^{\circ} \mathbf{C}\right)$ \\
\hline$C A D M 1-\mathrm{M} 2$ & GTTTTTCGTTATTTGTTGTTTTC & GAAACCGCGAAATACGAACG & 117 & 59 \\
\hline$C A D M 1-\mathrm{U} 2$ & GTTTTTTGTTATTTGTTGTTTTTG & AAAACCACAAAATACAAACA & 117 & 59 \\
\hline$C A D M 1-\mathrm{M} 8$ & GTCGTCGTATATTGGGATTC & TCTCATTAACTATCCGCTCG & 110 & 58 \\
\hline$C A D M 1-\mathrm{U} 8$ & GTTGTTGTATATTGGGATTT & TCTCATTAАСТАТСCACTCA & 110 & 58 \\
\hline$D A P K 1-\mathrm{M} 2$ & CGTTTGTAGGGTTTTTATTGGTC & CTACCGCTACGAATTACCGA & 161 & 60 \\
\hline$D A P K 1-\mathrm{U} 2$ & TGTTTGTAGGGTTTTTATTGGTTG & CCTACCACTACAAATTACCA & 162 & 60 \\
\hline$D A P K 1-\mathrm{M} 3$ & GTTTTTATTGGTCGTTTGTC & GACGTTAACTCGATCCGACT & 102 & 58 \\
\hline$D A P K 1-\mathrm{U} 3$ & TTTTATTGGTTGTTTGTTGG & CCCAACATTAACTCAATCCA & 103 & 58 \\
\hline$J A M 3-\mathrm{M} 4$ & CGTAGTTAGGGTTGGGATTC & GAAATCCGACGACTATCCGA & 138 & 60 \\
\hline JAM3-U4 & TGTAGTTAGGGTTGGGATTT & CAAAATCCAACAACTATCCA & 139 & 60 \\
\hline
\end{tabular}

Abbreviations: Tm: Annealing temperature

to have CIN2 were used to detect the expression of P16 (Dako, Denmark). Immunostaining involved use of the EnVision detection system (Dako, Denmark) according to the manufacturer's protocol.

\section{Statistical analysis}

Differences in detection rates between cervical cancer and normal cervical specimens by methylation markers were analyzed by chi-square or Fisher's exact test. ROC curves and their cut-off values were determined according to relative methylation levels obtained with QMSP. Pyrosequencing results were analyzed by MannWhitney test. Diagnostic performance for triage for methylation markers after hrHPV DNA and cytology testing was expressed as sensitivity, specificity, PPV and NPV with a cut-off for CIN2+ or CIN3+ respectively. All statistical analyses involved use of SPSS 18.0 (SPSS Inc., Chicago, IL, USA). P $<0.05$ was considered statistically significant.

\section{ACKNOWLEDGMENTS AND FUNDINGS}

This work was supported by the National High Technology Research and Development Program ("863" Program) of China (No. 2014AA020605, No. 2012AA02A507) and National Natural Science Foundation of China (No. 81272857).

\section{CONFLICTS OF INTEREST}

The authors declare no conflict of interest regarding the publication of this paper.

\section{REFERENCES}

1. Bray F, Ren JS, Masuyer E, Ferlay J. Global estimates of cancer prevalence for 27 sites in the adult population in 2008. Int J Cancer. 2013; 132:1133-1145.

2. Ferlay J, Soerjomataram I, Ervik M, Dikshit R, Eser S, Mathers C, Rebelo M, Parkin D, Forman D, Bray F. GLOBOCAN 2012 v1. 0, Cancer Incidence and Mortality Worldwide: IARC CancerBase No. 11. Lyon, France: International Agency for Research on Cancer; 2013. Visit: http://globocan iarc fr. 2014.

3. Zhao FH, Lewkowitz AK, Hu SY, Chen F, Li LY, Zhang QM, Wu RF, Li CQ, Wei LH, Xu AD, Zhang WH, Pan QJ, Zhang X, Belinson JL, Sellors JW, Smith JS, et al. Prevalence of human papillomavirus and cervical intraepithelial neoplasia in China: a pooled analysis of 17 population-based studies. Int J Cancer. 2012; 131:2929-2938.

4. Shi JF, Qiao YL, Smith JS, Dondog B, Bao YP, Dai M, Clifford GM, Franceschi S. Epidemiology and prevention of human papillomavirus and cervical cancer in China and Mongolia. Vaccine. 2008; 26:M53-59.

5. Saxena U, Sauvaget C, Sankaranarayanan R. Evidencebased screening, early diagnosis and treatment strategy of cervical cancer for national policy in low- resource countries: example of India. Asian Pac J Cancer Prev. 2012; 13:1699-1703.

6. Cuzick J, Clavel C, Petry KU, Meijer CJ, Hoyer H, Ratnam S, Szarewski A, Birembaut P, Kulasingam S, Sasieni P, Iftner T. Overview of the European and North American studies on HPV testing in primary cervical cancer screening. Int J Cancer. 2006; 119:1095-1101.

7. Mayrand MH, Duarte-Franco E, Rodrigues I, Walter SD, Hanley J, Ferenczy A, Ratnam S, Coutlee F, Franco EL, Canadian Cervical Cancer Screening Trial Study G. Human 
papillomavirus DNA versus Papanicolaou screening tests for cervical cancer. N Engl J Med. 2007; 357:1579-1588.

8. Bulkmans NW, Berkhof J, Rozendaal L, van Kemenade FJ, Boeke AJ, Bulk S, Voorhorst FJ, Verheijen RH, van Groningen K, Boon ME, Ruitinga W, van Ballegooijen M, Snijders PJ, Meijer CJ. Human papillomavirus DNA testing for the detection of cervical intraepithelial neoplasia grade 3 and cancer: 5 -year follow-up of a randomised controlled implementation trial. Lancet. 2007; 370:1764-1772.

9. Baseman JG, Koutsky LA. The epidemiology of human papillomavirus infections. J Clin Virol. 2005; 32:S16-24.

10. Wentzensen N, Sherman ME, Schiffman M, Wang SS. Utility of methylation markers in cervical cancer early detection: appraisal of the state-of-the-science. Gynecol Oncol. 2009; 112:293-299.

11. Kim JH, Choi YD, Lee JS, Lee JH, Nam JH, Choi C. Assessment of DNA methylation for the detection of cervical neoplasia in liquid-based cytology specimens. Gynecol Oncol. 2010; 116:99-104.

12. Vasiljevic N, Scibior-Bentkowska D, Brentnall AR, Cuzick J, Lorincz AT. Credentialing of DNA methylation assays for human genes as diagnostic biomarkers of cervical intraepithelial neoplasia in high-risk HPV positive women. Gynecol Oncol. 2014; 132:709-714.

13. Eijsink JJ, Lendvai A, Deregowski V, Klip HG, Verpooten G, Dehaspe L, de Bock GH, Hollema H, van Criekinge W, Schuuring E, van der Zee AG, Wisman GB. A four-gene methylation marker panel as triage test in high-risk human papillomavirus positive patients. Int J Cancer. 2012; 130:1861-1869.

14. Szalmas A, Konya J. Epigenetic alterations in cervical carcinogenesis. Semin Cancer Biol. 2009; 19:144-152.

15. Overmeer RM, Henken FE, Bierkens M, Wilting SM, Timmerman I, Meijer CJ, Snijders PJ, Steenbergen RD. Repression of MAL tumour suppressor activity by promoter methylation during cervical carcinogenesis. J Pathol. 2009; 219:327-336.

16. Steenbergen RD, Kramer D, Braakhuis BJ, Stern PL, Verheijen RH, Meijer CJ, Snijders PJ. TSLC1 gene silencing in cervical cancer cell lines and cervical neoplasia. J Natl Cancer Inst. 2004; 96:294-305.

17. Koeneman MM, Kruitwagen RF, Nijman HW, Slangen BF, Van Gorp T, Kruse AJ. Natural history of high-grade cervical intraepithelial neoplasia: a review of prognostic biomarkers. Expert Rev Mol Diagn. 2015; 15:527-546.

18. Tornesello ML, Buonaguro L, Giorgi-Rossi P, Buonaguro FM. Viral and cellular biomarkers in the diagnosis of cervical intraepithelial neoplasia and cancer. Biomed Res Int. 2013; 2013:519-619.

19. Saavedra KP, Brebi PM, Roa JC. Epigenetic alterations in preneoplastic and neoplastic lesions of the cervix. Clin Epigenetics. 2012; 4:13.

20. Overmeer RM, Louwers JA, Meijer CJ, van Kemenade FJ, Hesselink AT, Daalmeijer NF, Wilting SM, Heideman DA,
Verheijen RH, Zaal A, van Baal WM, Berkhof J, Snijders PJ, Steenbergen RD. Combined CADM1 and MAL promoter methylation analysis to detect (pre-)malignant cervical lesions in high-risk HPV-positive women. Int J Cancer. 2011; 129:2218-2225.

21. Qu Y, Dang S, Hou P. Gene methylation in gastric cancer. Clin Chim Acta. 2013; 424:53-65.

22. Jones PA. Functions of DNA methylation: islands, start sites, gene bodies and beyond. Nat Rev Genet. 2012; 13:484-492.

23. Steenbergen RD, Snijders PJ, Heideman DA, Meijer CJ. Clinical implications of (epi)genetic changes in HPVinduced cervical precancerous lesions. Nat Rev Cancer. 2014; 14:395-405.

24. Yang N, Eijsink JJ, Lendvai A, Volders HH, Klip H, Buikema HJ, van Hemel BM, Schuuring E, van der Zee AG, Wisman GB. Methylation markers for CCNA1 and C13ORF18 are strongly associated with high-grade cervical intraepithelial neoplasia and cervical cancer in cervical scrapings. Cancer Epidemiol Biomarkers Prev. 2009; 18:3000-3007.

25. Siegel EM, Riggs BM, Delmas AL, Koch A, Hakam A, Brown KD. Quantitative DNA methylation analysis of candidate genes in cervical cancer. PLoS One. 2015; 10:e0122495.

26. Yang N, Nijhuis ER, Volders HH, Eijsink JJ, Lendvai A, Zhang B, Hollema H, Schuuring E, Wisman GB, van der Zee AG. Gene promoter methylation patterns throughout the process of cervical carcinogenesis. Cell Oncol. 2010; 32:131-143.

27. Bierkens M, Hesselink AT, Meijer CJ, Heideman DA, Wisman GB, van der Zee AG, Snijders PJ, Steenbergen RD. CADM1 and MAL promoter methylation levels in hrHPVpositive cervical scrapes increase proportional to degree and duration of underlying cervical disease. Int J Cancer. 2013; 133:1293-1299.

28. Mersakova S, Visnovsky J, Holubekova V, Nachajova M, Kudela E, Danko J, Lasabova Z. Detection of methylation of the promoter region of the MAL and CADM1 genes by pyrosequencing in cervical carcinoma. Neuro Endocrinol Lett. 2014; 35:619-623.

29. Sun LL, Cao DY, Yang JX, Li H, Zhou XR, Song ZQ, Cheng XM, Chen J, Shen K. Population-based case-control study on DAPK1, RAR-beta2 and MGMT methylation in liquid-based cytology. Arch Gynecol Obstet. 2012; 285:1433-1439.

30. Boers A, Bosgraaf RP, van Leeuwen RW, Schuuring E, Heideman DA, Massuger LF, Verhoef VM, Bulten J, Melchers WJ, van der Zee AG, Bekkers RL, Wisman GB. DNA methylation analysis in self-sampled brush material as a triage test in hrHPV-positive women. Br J Cancer. 2014; 111:1095-1101.

31. Eijsink JJ, Yang N, Lendvai A, Klip HG, Volders HH, Buikema HJ, van Hemel BM, Voll M, Coelingh Bennink HJ, 
Schuuring E, Wisman GB, van der Zee AG. Detection of cervical neoplasia by DNA methylation analysis in cervicovaginal lavages, a feasibility study. Gynecol Oncol. 2011; 120:280-283.

32. zur Hausen H. Papillomaviruses causing cancer: evasion from host-cell control in early events in carcinogenesis. J Natl Cancer Inst. 2000; 92:690-698.

33. Baileff A. Cervical screening: patients' negative attitudes and experiences. Nurs Stand. 2000; 14:35-37.

34. Rogstad KE. The psychological impact of abnormal cytology and colposcopy. BJOG. 2002; 109:364-368.

35. Kinney WK, Manos MM, Hurley LB, Ransley JE. Where's the high-grade cervical neoplasia? The importance of minimally abnormal Papanicolaou diagnoses. Obstet Gynecol. 1998; 91:973-976.

36. Wright TC, Jr., Massad LS, Dunton CJ, Spitzer M, Wilkinson EJ, Solomon D. American Society for C and Cervical Pathology-sponsored Consensus C. 2006 consensus guidelines for the management of women with cervical intraepithelial neoplasia or adenocarcinoma in situ. Am J Obstet Gynecol. 2007; 197:340-345.

37. Massad LS, Einstein MH, Huh WK, Katki HA, Kinney WK, Schiffman M, Solomon D, Wentzensen N, Lawson HW, Conference ACG. 2012 updated consensus guidelines for the management of abnormal cervical cancer screening tests and cancer precursors. Obstet Gynecol. 2013; 121:829-846.

38. Arbyn M, Sasieni P, Meijer CJ, Clavel C, Koliopoulos G, Dillner J. Chapter 9: Clinical applications of HPV testing: a summary of meta-analyses. Vaccine. 2006; 24 Suppl 3:S3/78-89.

39. Schiffman M, Solomon D. Findings to date from the ASCUS-LSIL Triage Study (ALTS). Arch Pathol Lab Med. 2003; 127:946-949.

40. Kurman RJ, Cancer IAfRo and Organization WH. (2014). WHO classification of tumours of female reproductive organs: International Agency for Research on Cancer.
41. Martin-Padura I, Lostaglio S, Schneemann M, Williams L, Romano M, Fruscella P, Panzeri C, Stoppacciaro A, Ruco L, Villa A, Simmons D, Dejana E. Junctional adhesion molecule, a novel member of the immunoglobulin superfamily that distributes at intercellular junctions and modulates monocyte transmigration. J Cell Biol. 1998; 142:117-127.

42. Palmeri D, van Zante A, Huang CC, Hemmerich S, Rosen SD. Vascular endothelial junction-associated molecule, a novel member of the immunoglobulin superfamily, is localized to intercellular boundaries of endothelial cells. J Biol Chem. 2000; 275:19139-19145.

43. Mandicourt G, Iden S, Ebnet K, Aurrand-Lions M, Imhof BA. JAM-C regulates tight junctions and integrinmediated cell adhesion and migration. J Biol Chem. 2007; 282:1830-1837.

44. Hajjari M, Behmanesh M, Sadeghizadeh M, Zeinoddini M. Junctional adhesion molecules 2 and 3 may potentially be involved in progression of gastric adenocarcinoma tumors. Med Oncol. 2013; 30:380.

45. Langer HF, Orlova VV, Xie C, Kaul S, Schneider D, Lonsdorf AS, Fahrleitner M, Choi EY, Dutoit V, Pellegrini M, Grossklaus S, Nawroth PP, Baretton G, Santoso S, Hwang ST, Arnold B, et al. A novel function of junctional adhesion molecule-C in mediating melanoma cell metastasis. Cancer Res. 2011; 71:4096-4105.

46. Fuse C, Ishida Y, Hikita T, Asai T, Oku N. Junctional adhesion molecule-C promotes metastatic potential of HT1080 human fibrosarcoma. J Biol Chem. 2007; 282:8276-8283.

47. Solomon D, Nayar R. (2004). The Bethesda System for reporting cervical cytology: definitions, criteria, and explanatory notes: Springer Science \& Business Media. 